University of Pennsylvania Carey Law School

Penn Law: Legal Scholarship Repository

Faculty Scholarship at Penn Law

$6-2002$

\title{
Bounded Evaluation: Cognition, Incoherence, and Regulatory Policy
}

Cary Coglianese

University of Pennsylvania Carey Law School

Follow this and additional works at: https://scholarship.law.upenn.edu/faculty_scholarship

Part of the Administrative Law Commons, and the Antitrust and Trade Regulation Commons

\section{Repository Citation}

Coglianese, Cary, "Bounded Evaluation: Cognition, Incoherence, and Regulatory Policy" (2002). Faculty Scholarship at Penn Law. 1215.

https://scholarship.law.upenn.edu/faculty_scholarship/1215

This Response or Comment is brought to you for free and open access by Penn Law: Legal Scholarship Repository. It has been accepted for inclusion in Faculty Scholarship at Penn Law by an authorized administrator of Penn Law: Legal Scholarship Repository. For more information, please contact PennlawIR@law.upenn.edu. 


\title{
COMMENTS
}

\section{Bounded Evaluation: Cognition, Incoherence, and Regulatory Policy}

\author{
Cary Coglianese*
}

To many observers, the words "predictably incoherent" describe well the fragmented network of rules and regulatory institutions that has grown up in the United States over the last century.' Hundreds of federal agencies collectively publish thousands of new regulations each year. ${ }^{2}$ Federal

* Associate Professor of Public Policy and Chair, Regulatory Policy Program, John F. Kennedy School of Government. For helpful and coherent comments on an earlier version of this Article, I am grateful to David Lazer, Todd Olmstead, Robert Stavins, and David Weil.

1. See Robert A. Kagan, Adversarjal Legalism: The American W a y of Law 198 (2001) ("Institutional fragmentation results in overlapping, imperfectly coordinated regulation by numerous local, state, and federal agencies, which may be dominated by different political parties with different regulatory policy preferences."); OFFICE OF Management and Budget, More Benefits, Fewer Burdens: Creating a Regulatory SYSTEM THAT WORKS FOR THE AMERICAN PEOPLE (1996), available at http://whitehouse.gov/omb/inforeg/3_year_report.html ("Given each agency's legitimate focus on its own mission, and the fact that the Federal government is a complex organization with programs dispersed among many different agencies, sub-agencies, and offices, it is not unusual to find regulations that are inconsistent, incompatible, or duplicative."); E. Donald Elliott \& Gail Chamley, Toward Bigger Bubbles, 13 Forum APPLIED REs. \& PUB. POL'Y 48 (1998) (arguing that the "fragmentation of policymaking into separate regulatory programs makes it virtually impossible for comparative risk priorities to be set on a rational basis that even approaches maximizing the social benefit from a given level of investment"); Alice M. Rivlin, Rationalism and Redemocratization: Time for a Truce, in WORST THINGS FIRST? 21, 26 (Adam M. Finkel \& Dominic Golding eds., 1994) ("[L]eft to its own devices, the political system comes up with what almost anybody would think of as bizarre answers and misallocations of resources-with too much spent on relatively low-risk phenomena and, at the same time, a relative starving of problems where the risks might be very high.").

2. Office of the Federal Register, The United States Government Manual, 2001/2002 app. C, at 653-61 (2001) (listing more than 300 federal agencies whose regulations appear in the Code of Federal Regulations). See also John D. Graham, Speech to Weidenbaum Center Forum, Presidential Management of the Regulatory State (Dec. 17, 2001), available at http://www.whitehouse.gov/omb/inforeg/graham_speech121701.html 
responsibility for food safety rests in a dozen different regulatory agencies, operating under at least thirty-five different statutes. ${ }^{3}$ At least eight major agencies are charged with responsibility for reducing the risk of exposure to hazardous substances under more than two dozen statutes, each with their own structure and standards. ${ }^{4}$ Congress has created more than 200 committees and subcommittees, many of which oversee the development of regulatory policy. ${ }^{5}$ By some estimates, the U.S. Environmental Protection Agency has had as many as ninety congressional committees and subcommittees overseeing its work. ${ }^{6}$

Regulatory agencies not only report to Congress, but also find themselves repeatedly wrangling with a variety of other actors and institutions, including the Office of Management and Budget, the White House, the courts, and the media. ${ }^{7}$ Internally, these same regulatory agencies are divided across program areas and by professional specialization. Moreover, the intemal and external fragmentation of policy authority plays itself out at the level of state and local governments, which interact with the federal govemment and add another layer of complexity to the making and implementation of regulatory policy. Given the extensive fragmentation of policymaking authority, it should come as no surprise that regulation in the United States appears so complex and incoherent.

In their article, Predictably Incoherent Judgments, Cass Sunstein, Daniel Kahneman, David Schkade, and Ilana Ritov advance a cognitive explanation for incoherence in government regulation. ${ }^{8}$ They argue that decisionmakers tend to think within narrowly-conceived categories and have difficulty translating their normative judgments into concrete terms, such as dollar amounts. ${ }^{9}$ Both of these factors, they suggest, result in patterns of micro-level

("[T]here are over 100 federal agencies and subagencies with regulatory mandates from Congress. They chum out 4,500 new rules each year.").

3. Institute of Medicine \& National Research Council, Ensuring Safe Food: FROM PRODUCTION TO CONSUMPTION 26 (1998), available at http://books.nap.edu/books/0309065593/html/26.html (noting that "[a]t least a dozen federal agencies implementing more than 35 statutes make up the federal part of the food safety system").

4. See, e.g., Stephen Breyer, Breaking the Vicious Circle 8 (1993) ("[R]egulation designed to screen out risky substances, including cancer-causing substances, is embodied in many different regulatory programs-indeed in at least twenty-six different statutes administered by at least eight different agencies.").

5. David C. King, Turf Wars: How Congressional Committees Claim Jurisdiction 71 (1997); Norman J. Ornstein, Thomas E. Mann \& Michael J. Malbin, Vital STATISTICS ON CONGRESS, 1999-2000, at 113 (2000).

6. KING, supra note 5, at 71 .

7. See, e.g., Peter L. Strauss, Todd Rakoff, Roy A. Schotland \& Cynthia Farina, Gellhorn and Byse's Administrative law: Cases and Comments 50 (9th ed. 1995) (illustrating the web of institutional interactions confronting federal agencies).

8. Cass Sunstein, Daniel Kahneman, David Schkade \& Ilana Ritov, Predictably Incoherent Judgments, 54 STAN. L. REV. 1153 (2002).

9. $I d$. 
judgments that make little sense when viewed from a macro-level perspective across different categories. They argue that decisions that seem sensible when viewed in isolation, or within a single category, result in patterns that are globally inconsistent or suboptimal.

Sunstein et al. rightly call attention to the effects of cognition on regulatory policymaking, and especially to problems associated with narrow, ad hoc decisionmaking. In this essay, I argue that the effects of cognitive limitations are probably even more pronounced than Sunstein et al.'s article suggests. They argue that cognitive tendencies such as category-bound thinking lead to incoherent regulatory policies, but I will argue that, in addition, these same kinds of cognitive constraints can affect judgments about incoherence itself. If people have a tendency to focus on one category at a time in making judgments, then evaluations that judge different policies to be incoherent will tend to be bounded as well. Consequently, it will be still more difficult than Sunstein et al.'s article seems to imply to design and evaluate institutional reforms to reduce incoherence in regulatory policy.

In the following pages, I first introduce a tension between what I refer to as instrumental and comparative coherence, arguing that variation in policies that appears to make little sense when policies are compared with each other may be quite sensible for instrumental reasons. I then examine Sunstein et al.'s claim to have discovered striking incoherence in the penalty levels across regulatory statutes. I argue that when considered from a broader perspective the apparently obvious incoherence in some of these penalty levels is not nearly as obvious as it first seems. Finally, I argue that the same kind of bounded evaluation problem arises when regulations are judged to be incoherent based on variation in their cost-effectiveness.

Regulatory policies that appear incoherent when compared along one dimension or evaluated with only one purpose in mind will not necessarily be properly viewed as incoherent once other dimensions or purposes are taken into account. Indeed, because the conditions underlying regulatory policy are both varied and complex, judgments about incoherence will be unavoidably difficult (and even sometimes incoherent) since regulatory policies vary along multiple dimensions and people have a tendency to focus only on one dimension at a time.

\section{Conceptualizing Regulatory InCOHERENCE}

Fragmented regulatory institutions make it more likely that regulatory policy will vary in its standards, procedures, penalties, and resources, such that seemingly similar cases will not always be treated alike. Sunstein et al. frame much of their discussion of regulatory incoherence around the considerable variation in the civil penalties that administrative agencies can impose on those 
who have violated federal statutes and regulations. ${ }^{10}$ Numerous statutes permit administrative agencies to impose civil, and sometimes criminal, penalties on regulated actors. The statutes typically provide for maximum penalties that can be imposed, and the pattern of maximum penalties across federal regulatory agencies varies considerably, from $\$ 500$ to as much as $\$ 1,000,000$ for certain criminal penalties." Some statutes place maximum limits on penalties per violation, while others impose limits per day of violation and still others stipulate minimum penalties that must be imposed for certain types of violations.

As Sunstein et al. note, the pattern of civil penalties across regulatory regimes is not something which has garnered a great deal of attention from scholars and policymakers. ${ }^{2}$ In 1990, for example, Congress increased the maximum civil penalties for OSHA violations but, as would be predicted from Sunstein et al.'s argument, legislators apparently failed to make any explicit comparison to other agencies' penalties. The legislative record only shows that legislators emphasized how much more revenue could be raised by increasing OSHA's penalties and how low the earlier penalties had been relative to the importance of worker safety.

Notwithstanding the apparent lack of legislative debate comparing the size of different penalties, in other contexts scholars and analysts have sometimes paid attention to differences in the size of administratively-imposed penalties. One of the earliest studies of civil penalties included a chart of different agencies' penalties and noted the "varying amounts of money" associated with civil penalties that "resulted from a series of relatively unstudied, ad hoc legislative acts." 13 More recent studies and commentary have also made explicit comparisons of civil penalty policies across different agencies. ${ }^{14}$ In

10. Id. at 1186-1194.

11. See id.app. D, at 1211-1213. The $\$ 500$ maximum is for unknowingly violating the key provision of the Wild Bird Conservation Act. 16 U.S.C. \$ 4912(c). The \$1 million maximum is a criminal penalty for organizations that knowingly transport, treat, or store hazardous waste without a permit and knowingly put a person in imminent danger of death or serious bodily injury. 42 U.S.C. $\S 6928(\mathrm{e})$. For charts showing the variation in civil penalties across agencies, see Harvey J. Goldschmid, An Evaluation of the Present and Potential Use of Civil Money Penalties as a Sanction by Federal Administrative Agencies, in 2 RECOMMENDATIONS AND REPORTS OF THE AdMINISTRATIVE CONFERENCE OF THE UNited STATES 896, 955-56 (1972) and Sunstein et al., supra note 8, at 1190, 1211-1213.

12. See Sunstein et al., supra note 8, at 1160.

13. Goldschmid, supra note 11 , at 956.

14. See, e.g., U.S. Gen. Accounting Office, implementation of Selected Agencies' Civil Penalty Relief Policies for Small Entities (2001) (explicitly comparing five federal agencies' policies for moderating civil penalties for small businesses); U.S. Gen. Accounting Office, Views on Proposed Legislation on Civil Penalties for Nuclear Safety Violations by NonProfit Contractors, (2001) (Mar. 22, 2001 testimony of Gary L. Jones) (arguing against a DOE exemption of nonprofit contractors from penalties on the ground that the NRC and other regulatory agencies impose penalties on these same contractors); Testimony of Roger J. Marzulla, former Assistant 
addition, researchers have noted the variation in civil penalties imposed by single agencies applying different statutes, ${ }^{15}$ and regulatory agencies have sought to foster consistency in their own civil penalties by developing guidelines for the imposition of such penalties. ${ }^{16}$ While the Sunstein et al. article is by no means the first to highlight issues of consistency and coherence in civil penalties, variation in the size of penalties across agencies has certainly escaped the kind of attention that scholars and policy makers have given to other differences in regulatory policy, such as cross-agency variation in the cost-effectiveness of regulations. ${ }^{17}$

Sunstein et al. argue that the variation they observe in civil penalties reveals "serious anomalies" creating significant injustice in the overall system of federal regulation. ${ }^{18}$ In particular, they draw attention to the disparity between the maximum penalties for violations of federal Occupational Safety and Health Act ("OSHA") regulations and the maximum penalties for violations of the Wild Bird Conservation Act. ${ }^{19}$ A serious violation of OSHA requirements can result in a civil penalty of up to $\$ 7000$, while the illegal importation of exotic wild birds can yield a penalty as high as $\$ 25,000$. Sunstein et al. claim that even though there is substantial coherence within each regulatory regime, something is awry when the penalties associated with the importation of exotic birds are more than three times as large as the penalties associated with putting workers' lives at risk.

Other examples of varied, and potentially anomalous, penalties can easily be found, especially when comparing penalties for the same offense across different jurisdictions. Consider one of the most well known of all civil

Attomey General, Environment and Natural Resources Division, before the House Judiciary Committee, Subcommittee on Commercial and Administrative Law (May 7, 1998), available at 1998 WL 233950 (advocating congressional reform of criminal penalty provisions by arguing that regulatory "agencies rank violation of their regulations as the highest priority criminal offense, giving little or no thought to the relationship between penalties imposed by that agency and [the] rest of the criminal law regime"). See also William Funk, Close Enough for Government Work? Using Informal Procedures for Imposing Administrative Penalties, 24 SETON HALL L. REv. 1 (1993) (describing variation in procedures used in assessing administrative penalties and urging consideration of an amendment to the Administrative Procedure Act to provide greater uniformity).

15. See Jonathan M. Karpoff, John R. LotT, JR., \& Graeme Rankine, Environmental Violations, Legal Penalties, and Reputational Costs 13 (1999) (reporting differences in environmental regulatory awards imposed across different media); Kell.y KRISTEN LEAR, An EMPIRICAl EXAmination of EPA Administrative PENAlties 32, 35, 40 (1998) (reporting variation in EPA fines across different statutes).

16. See, e.g., Health Care Financing Administration, Civil Money Penalties for Nursing Homes, 64 Fed. Reg. 13354-01 (Mar. 18, 1999).

17. See BREYER, supra note 4, at 24-27; see also infra notes 60-66 and accompanying text.

18. Sunstein et al., supra note 8 , at 1191.

19. Id. They also compare the penalties for OSHA violations with the awards available in cases of employment discrimination. 
penalties: the parking ticket. The current penalty for unauthorized parking in an area designated for the handicapped is $\$ 25$ on the grounds of Harvard University or at the Boston campus of the University of Massachusetts, but it is $\$ 75$ in the city of Boston and $\$ 100$ in the city of Cambridge. In New York City, a handicapped parking violation yields a $\$ 180$ penalty. Except in the city of Boston, these penalties are higher than the penalties for parking next to a fire hydrant: \$15 at Harvard University and the University of Massachusetts; $\$ 75$ in Boston; $\$ 25$ in Cambridge; and $\$ 55$ in New York City.

Even within the same jurisdiction, penalties can vary across different regulatory contexts. Children in day care centers in New York are protected by maximum penalties of $\$ 200$ a day imposed for regulatory violations that place children "at risk of physical, mental, or emotional harm," and $\$ 500$ a day for violations that place them "at risk of death, serious or protracted disfigurement, or protracted impairment of physical or emotional health." ${ }^{20}$ Interestingly, the able-bodied person who parks in a handicapped parking spot in New York City will pay about the same penalty in any given day as will someone in the city who is found to have violated day care regulations in a way that puts a child at risk of harm. ${ }^{21}$ Residents in nursing homes, in contrast, are protected by a uniform maximum penalty level of up to $\$ 1000$ per day of violation. ${ }^{22}$

As these examples show, civil penalties can vary greatly across a broad range of regulations. Variation in regulatory penalties, however, does not necessarily equate to a problem of regulatory incoherence. Variation simply means that there are different penalties associated with various offenses, not necessarily that they are incoherent. In contrast, incoherence describes a pattern of penalties that, to use Sunstein et al.'s words, "do not make sense." ${ }^{23}$ The way in which a pattem of penalties or other regulatory policies makes no sense should be thought of in normative terms-not positive or empirical ones. It may be possible to explain the variation in policies empirically in terms of various cognitive, political, or social factors, but still also possible to criticize the overall pattern of penalties in normative terms.

20. The penalty for a Class II violation of New York's day care regulations is a maximum of $\$ 200$ per day. N.Y. COMP. CODES R. \& REGS. tit. 18, $\$ 413.3$ (2001). The penalty for Class I violations that place a child at "risk of death, serious or protracted disfigurement, or protracted impairment of physical or emotional health" is a maximum of $\$ 500$ per day. Id.

21. Actually, the penalty for handicapped parking violations has no daily limit, but the penalty for day care violations does. Also, the penalties for Class III violations of day care regulations - those violations which do not place children at risk of harm-is only $\$ 50$ per day, slightly less than for general parking violations in New York City.

22. N.Y. COMP. CODES R. \& REGS. tit. 18, $\$ 414.4$ (2001) (specifying maximum penalties of up to $\$ 1000$ per day for violations of nursing home regulations).

23. Sunstein et al., supra note 8, at 1156. The particular test of coherence for Sunstein et al. is whether "the ranking of two or more cases [is] the same when they are directly compared and when they are judged in isolation." Id. at 1172. 
Regulatory outcomes that are incoherent can be justifiably criticized as inefficient, unfair, or perhaps both. From the standpoint of overall welfare, incoherent outcomes fail to deploy resources in a socially optimal way, such as by bringing too little regulatory attention to bear on the most significant public problems and too much attention on the least significant. ${ }^{24}$ Incoherent regulatory policies can also result in situations where some individuals find themselves more protected than similarly situated others and where some individuals and firms are more scrutinized by governmental oversight than are similarly situated others.

Regulations "do not make sense" in a variety of ways. I will distinguish between two types of coherence: instrumental coherence and comparative coherence. ${ }^{25}$ To test for instrumental coherence is to consider whether regulatory strategies or means are consistent with appropriate regulatory goals or ends. A regulatory policy fails to make instrumental sense if it fails to achieve its objectives or if it produces more harm than good. Regulatory policies are often criticized for being instrumentally incoherent because they are ineffectual, produce unintended consequences, or impose far too many costs for the social benefits they achieve. ${ }^{26}$

Judging a regulation to be instrumentally incoherent depends only on making a judgment about the particular regulation. While knowledge of the performance of other regulations may provide clues that help in judging the instrumental coherence of another regulation, a judgment about the instrumental coherence of a given regulation can be made in isolation of judgments about other regulations. In contrast, a regulation fails to make sense comparatively if it turns out to be inconsistent with other regulations of either the same general type or other types altogether. This inconsistency could arise between ends, between means, or between the relationships between means and ends.

Sunstein et al. usefully distinguish further between two types of comparative coherence: within category and across category coherence. ${ }^{27}$ Regulations or their outcomes can be said to be coherent within category if they are consistent with other regulations or outcomes of their same general type. ${ }^{28}$ Regulations or their outcomes can be said to be coherent across

24. Of course, uniform policies can also result in a misallocation of resources when they are applied across a varied range of conditions. For a discussion of the unreasonableness of applying uniform rules, see EUGENE BARDACH \& ROBERT A. KAGAN, GOING BY THE BOOK: THE PROBLEM OF REgULATORY UNREASONABLENESS 58-71 (1982).

25. This distinction seems implicit in Sunstein et al., supra note 8, at 1160 ("[W]e do not suggest that coherence is sufficient to produce good outcomes.").

26. W. Kip Viscusi, Fatal Tradeoffs: Public and Private Responsibilities for RISK 248 (1992) (noting widespread criticism that government regulations are costly and "ineffective in promoting their intended objectives").

27. Sunstein et al., supra note 8, at 1154, 1157, 1163.

28. Id. at 1172 
category only if the overall pattern of regulations or outcomes makes sense across different regulatory categories. ${ }^{29}$

To illustrate these distinctions, return to the example of civil penalties for regulatory violations. Such penalties would be judged instrumentally incoherent if they were set at a level that failed to achieve the goal of reducing the socially undesirable ends that they were intended to deter. For instance, we might imagine a world in which the maximum penalty for a serious violation of an OSHA regulation was only a nickel per year. 30 It would "make no sense" instrumentally to adopt such a ridiculously low penalty because that level would effectively have the same deterrent effect as no penalty at all. ${ }^{31}$ On the other hand, a maximum penalty of a nickel per year could be viewed as comparatively consistent if that penalty did not seem out of line with the penalties for other types of violations. If the maximum penalties for nonserious OSHA violations were less than a nickel per year, then having maximum penalties for serious OSHA violations of a nickel per year would seem comparatively coherent within the category of OSHA violations. If maximum penalties for other less serious regulatory violations outside $\mathrm{c}^{f}$ OSHA were also lower, then the nickel-per-year penalty could be thought of as comparatively coherent across categories.

In an ideal world we would expect a regulatory system to achieve both instrumental and comparative coherence. ${ }^{32}$ Yet achieving both is challenging in no small part because it requires decisionmakers to obtain competing types of information. Instrumental coherence tends to call for depth, while comparative coherence tends to call for breadth. To achieve instrumental coherence, regulatory designers focus on solving the problem at hand, on identifying concrete strategies to achieve relatively narrow regulatory goals. Comparative coherence, in contrast, requires decisionmakers to step back and assess the landscape, to make comparisons.

To be sure, efforts aimed at standardizing information collection and decision modeling across policy areas can lower the costs of making comparisons, and they are to be desired for this very reason. ${ }^{33}$ Yet even with much needed efforts of standardization, information will never be costless. Decisionmakers with limited time and resources confront choices about how to

29. Id.

30. Though obviously an extreme hypothetical, this example may resonate with sports fans who complain that penalties for technical fouls and other transgressions on the basketball court are comparably trivial. See Doug Robinson, Big-Time Players Pay SmallTime Fines, DESERET NEWS, Jan. 20, 2001.

31. Correspondingly, we could easily imagine a penalty that was ridiculously high, such as shutting down a facility entirely on the finding of one minor violation.

32. Cf. James E. Krier, On the Topology of Uniform Environmental Standards in a Federal System-And Why It Matters, 54 MD. L. REV. 1226 (1995) (calling for "wise" consistency in environmental regulation).

33. See infra note 86 and accompanying text. 
invest in information gathering, and one such choice is between gathering the information needed to achieve instrumental coherence and gathering that needed to achieve comparative coherence.

For some purposes, though, it will be necessary to invest in both kinds of information. If we are interested in assessing the comparative coherence of regulatory strategies, including the size of civil penalties, information about instrumental coherence will be necessarily relevant. This is because regulators often must adapt policies to different conditions to achieve instrumental coherence, employing different strategies for situations that may be similar in some respects but which differ in others. Since the social and economic conditions for which regulatory standards, practices, and penalties are designed vary, these standards, practices, and penalties also need to vary in order to achieve regulatory goals effectively. A well-crafted, instrumentally coherent system of regulatory policy will therefore exhibit a high degree of variation both within and across regulatory categories, and for this reason will be more likely to appear on the surface to be comparatively incoherent. ${ }^{34}$

$\therefore \quad$ This is not to say that instrumental reasons will always explain variation in regulatory outcomes, but simply that a fair and full assessment of the degree of comparative coherence in a regulatory system should take into account whether there are valid, instrumental reasons why regulatory strategies vary in seemingly incoherent ways. In other words, to identify comparative incoherence in regulatory strategies it will often be necessary to seek depth as well as breadth. Identifying comparative incoherence in such cases involves consideration of variation in the conditions and constraints across policy areas as well as variation in regulatory outcomes. To judge comparative coherence is therefore to ask whether the differences in these underlying conditions, as well as in the overarching goals, justify differences in regulatory strategies.

\section{InCOHERENCE AND Civil PENALTIES}

Sunstein et al. recognize the difficulties of identifying comparative coherence, but they also suggest that there are "obvious anomalies" across

34. It is quite possible, of course, that seeking instrumental coherence in a variety of separate regulatory realms will lead to genuine comparative incoherence across these realms. Myopic optimization on separate parts of a problem can result in the suboptimization of the larger problem. See GeORge L. Nemhauser \& LAURENCE A. Wolsey, INTEGER AND COMBinatorial Optimization 60, 393-94 (1988) (describing how "greedy" or "myopic" algorithms generally fail to yield optimal results). Certainly, this is easy to see when judging regulatory outcomes. A regulatory system filled with a series of instrumentally coherent policies aimed at trivial problems, but which left major problems completely unaddressed, would properly be judged incoherent in a comparative sense. For an excellent elucidation of this kind of argument, see BREYER, supra note 4, at 11 (describing the problem of "tunnel vision," whereby "each employee's individual conscientious performance effectively carries single-minded pursuit of a single goal too far, to the point where it brings about more hanm than good"). 
categories that would lead people to conclude that the overall system makes little sense. ${ }^{35}$ They point specifically to the $\$ 7000$ penalties available for OSHA violations and the $\$ 25,000$ penalties available for violations of the Wild Bird Conservation Act, claiming that "[i]t is extremely doubtful that the public would support that pattern of penalties, taken as a whole." ${ }^{36}$ As a matter of predicting public opinion, perhaps this is correct, especially if the public has little information about regulatory penalties and the conditions under which they are applied. Yet such judgments of incoherence can themselves be limited by people's cognitive capacities. When trying to compare two or more regulatory systems, people may focus simply on the perceived importance of the underlying regulatory goal when it would be relevant to take other factors into account in making an informed judgment about the coherence of different regulatory systems.

Individuals may have a tendency to "see" incoherence when on closer examination there is none. The same cognitive tendencies that Sunstein et al. have so carefully illuminated would lead us to expect that this would occur quite often. If individuals have a tendency to take up problems "one case at a time," they presumably have a tendency to focus only on one factor at a time when making comparisons across categories. This will lead them in some cases to focus on incoherence along one dimension, but to overlook other dimensions that might justify differences across categories.

The general point is that regulatory policies can sensibly and justifiably vary, and that ordinary people's judgments about what they find obviously incoherent may themselves be either incoherent or wrong. When it comes to regulatory violations, there are a number of possible reasons why civil penalties could sensibly vary even if more serious violations are backed up by lower penalties than are less serious violations. When other considerations are taken into account, differences that might seem obviously problematic may well be justified. For example, rather than an obvious case of incoherence, the case of OSHA civil penalties probably better illustrates the difficulties in judging incoherence across categories. Additional factors relevant to identifying incoherence in regulatory penalties would include the following.

\section{A. Existence of Other Liability}

In some cases, civil penalties will not be the only financial sanction confronting those who violate regulations. For example, employers who fail to provide a safe workplace can find themselves exposed to more than just the possibility of civil penalties imposed by the federal OSHA. They also can face

35. Sunstein et al., supra note 8, at 1186 . Elsewhere in the article, they also refer to "[s]candalously large inconsistencies" in policy, though it is not clear whether they have civil penalties in mind. $I d$. at 1156 .

36. Id. at 1191 ; see also id. at 1192. 
workers' compensation claims, tort liability (including possible punitive damages), and higher wages. ${ }^{37}$ Indeed, the violation of an OSHA standard may itself sometimes provide a basis for claims of negligence in tort litigation. In contrast, those who import wild birds in contravention of the federal statute face no similar exposure to additional liability. Hence, it can make sense to have lower administrative penalties for more serious regulatory offenses if offenders are also subject to other kinds of liability or non-regulatory penalties. ${ }^{38}$

\section{B. Availability of Alternative Remedies}

Regulators in some instances will also have available other remedies to ensure compliance or to correct problems created by regulatory violations. OSHA, for example, can obtain injunctive relief, such as closing down a workplace entirely; 39 but the Fish and Wildlife Service has no comparable injunctive relief available to it. Similarly, a handicapped person cannot move a car that is parked illegally in a spot designated for handicapped only, but, if necessary, firefighters can break into and move a car that is in the way of a fire hydrant. In those cases where injunctive relief or other alternative remedies are available, it makes sense that civil penalties would not be as high. Especially when injunctive remedies include shutting down a business, the effective penalties imposed on violators will be substantial regardless of the specific fine levied by statute. ${ }^{40}$

\section{The State of Mind of the Violators}

Sometimes those who violate regulations do not even know that they are doing so. All things being equal, civil penalties against those who unintentionally breach regulations probably do not need to be as large as those

37. See W. Kip Viscusi, John M. Vernon \& Joseph E. Harrington, Jr., ECONOMiCS OF REGULATION AND ANTITRUST 814 (2d ed. 1995) (noting that OSHA's civil penalties amount to no more than about $\$ 25$ million per year nationwide, compared with $\$ 70$ billion in higher wages associated with workplace risks, and workers' compensation premiums of more than $\$ 20$ billion).

38. In addition to government-imposed liability or penalties, there also can be negative market consequences associated with regulatory violations. Productivity may be diminished in firms that are cited for regulatory violations or, altematively, boosted in those firms that pass regulatory inspections. Workers generally demand higher wages in industries with larger safety risks. Customer reactions or responses by insurers may also be a consideration for firms which are cited for certain kinds of regulatory violations.

39. See 29 U.S.C. $§ 662$ (1999). In those cases where OSHA improperly fails to seek injunctive relief, the statute allows employees or their representatives to seek it themselves.

40. See BARDACH \& KAGAN, supra note 24, at 53 (noting that in junctive relief imposes an "expense [that] is usually equivalent to a much larger fine than a court would ever impose"). 
imposed against knowing or willful violators. ${ }^{41}$ The seemingly striking disparity between the $\$ 7000$ OSHA penalty and the $\$ 25,000$ wild bird penalty appears to be at least partially explainable on this basis. The $\$ 25,000$ maximum penalty under the Wild Bird Conservation Act is specifically for any person who "knowingly" violates the relevant regulations or for any person engaged in the business of importing exotic birds, who presumably knows or should know of the regulations. ${ }^{42}$ The Act assesses a maximum civil penalty of only $\$ 500$ for a person who otherwise violates its regulations. ${ }^{43}$ In comparison, OSHA authorizes a maximum penalty of $\$ 70,000$ for any employer who "willfully" violates worker safety regulations. ${ }^{44}$ The $\$ 7000$ maximum penalty is for employers who unintentionally violate the regulations. ${ }^{45}$ While subtle differences might be drawn between "knowingly" and "willfully," when the state of mind of the violator is taken into account it becomes less clear that the comparison between OSHA and Fish and Wildlife Service penalties is incoherent.

\section{Distance Between Legal Rule and Outcome of Concern}

Regulations aim to reduce undesirable outcomes in the world, but it is often infeasible to set a regulatory standard based directly on the undesirable outcome. Instead, regulators must often write standards that aim either at proxies for the outcome of concern or at other factors believed to be correlated with the outcome of concern. ${ }^{46}$ Perhaps lower penalties are justified for violations of regulations that rely on proxies or aim at behavior that is only correlated with the ultimate outcome of concern, even though the ultimate outcome may be more serious. Parking next to a fire hydrant does not itself cause fires, while parking in a handicapped parking spot does diminish access for those who are physically challenged. A well-designed regulatory system aimed at worker health and safety may require employers to complete various

41. It is not simply that those who knowingly or willfully violate regulations deserve larger penalties for punitive reasons. Since they knew of the law and broke it anyway, it may take a larger penalty to deter them from future violations or to send an optimal signal to other regulated entities that they should follow all the laws they know about. In those cases where violators unknowingly break the law, simply informing them of their obligations can sometimes go a long way toward getting them to achieve compliance and therefore the penalty will not need to be as large. See TOM R. TYler, Why PEOPLE OBEy THE LAw 3-5 (1990) (discussing reasons why people obey the law other than simply to avoid penalties).

42. 16 U.S.C. $\$ 4912(\mathrm{a})(1)(\mathrm{A})(2000)$.

43. Id. $\$ 4912(\mathrm{a})(1)(\mathrm{C})$.

44. 29 U.S.C. \$ 666(a) (1994). OSHA also adds a statutorily-required minimum penalty of $\$ 5000$ for willful violations, something which is absent from the Wild Bird Conservation Act's provisions. Id.

45. Id. $\$ 666(\mathrm{~b})$.

46. Stephen Breyer, Regulation AND ItS ReForm 104-05 (1982). 
forms, but completing government-required paperwork presumably is not as serious as the underlying goal of worker safety itself. ${ }^{47}$

\section{E. Type and Size of Regulatory Targets}

The behavioral impact of a civil penalty can vary depending on the resources of the regulated entity and the economic gains to the firm from contravening the regulation. For this reason, penalties for regulations that target individuals and small businesses need not be set at levels as high as those for other, less serious offenses that govern larger firms. ${ }^{48}$ In some states, for example, the penalties associated with violating state rules governing the operation of day care facilities are limited to no more than a couple hundred dollars per violation. ${ }^{49}$ In contrast, the Commodity Futures Trading Commission can impose up to $\$ 100,000$ or triple the economic gain for manipulating market prices. ${ }^{50}$ The Securities and Exchange Commission can impose penalties on firms up to $\$ 250,000$ or the amount of the economic gains from the violation (whichever is higher) for fraud or manipulation. ${ }^{51}$ This pattern does not necessarily mean that the well-being of children is valued less than fraud-free securities markets, nor does it mean that the civil penalties across these categories are incoherent. Rather, the pattern across these categories makes better sense if we consider that there are smaller economic gains to be had from violating day care standards than from committing securities fraud. ${ }^{52}$

47. The system of penalties for OSHA violations appears to take this factor into account, as non-serious violations, such as failures to file required paperwork, are distinguished from "serious" violations, which pose a substantial risk to worker safety. 29 U.S.C. \$ 666(k) (1994) (defining "serious" violations as those for which a "substantial probability that death or serious physical harm could result"). The same statute also allows OSHA to issue a simple notice of violation for "de minimis violations which have no direct or immediate relationship to safety or health." Id. §658(a).

48. Sometimes regulators have found that simply sending a letter to small businesses, notifying them of applicable regulations, is sufficient to induce compliance. See El.IZABETH SCHEeHle, Improving Small Business Environmental Compliance through Enforcement Mechanisms: A Case Study on Underground Storage Tanks (1999) (policy analysis exercise prepared for the Progressive Policy Institute).

49. ARIZ. REV. STAT. \$36-891 (2002) (maximum fine of $\$ 100$ per violation); CAL. HEALTH \& SAFETY CODE $\$ 1596 .($ West 2002) (general limit of $\$ 50$ per violation, not to exceed $\$ 150$ per day); DEL. CODE ANN. tit. 31, \$345 (2001) (\$100 maximum fine); MD. CODE ANN., FAM. LAW \$5-557.1 (2002) (\$250 fine for the first violation by a family day (are home).

50. 7 U.S.C. $\$ 9(2000)$.

51. 15 U.S.C. \$ $78 \mathrm{u}(\mathrm{d})(3)(\mathrm{B})(\mathrm{ii})(2000)$.

52. An interesting, and perhaps extreme, case of taking into account violators' resources can be found in Finland. Finnish traffic fines vary according to the violator's income-a system which recently resulted in highly-publicized case of a business executive receiving the equivalent of a $\$ 103,600$ fine for driving his motorcycle at 47 miles per hour in 


\section{F. Probability of Detecting Violations}

The deterrent effect of regulatory penalties depends not merely on their size, but also on the probability that a regulatory agency will detect violations of the applicable regulations. ${ }^{53}$ This probability will depend on the amount of inspection resources available to the regulatory agency, the number of regulated entities to be inspected, and the ease with which government inspectors can detect a violation. ${ }^{54}$ If less serious violations are harder to detect than more serious violations, regulatory agencies may need larger penalties, all things being equal, to achieve an optimal level of deterrence. ${ }^{55}$

\section{G. Probability of Imposing Penalties}

Once an agency detects a violation, it must then proceed through a process of imposing that penalty. Penalties that can be assessed directly by a regulatory agency will likely have a higher probability of being imposed than will

a 30 mile per hour zone. See Tech Executive Appeals \$100,000 Speeding Fine, L.A. TIMES, Jan. 15, 2002, at A4.

53. For prominent discussions of optimal deterrence, see Gary S. Becker, Crime and Punishment: An Economic Approach, 76 J. POL. ECON. 169 (1968) and A. Mitchell Polinsky \& Steven Shavell, The Optimal Use of Fines and Imprisonment, 24 J. PUB. ECON. 89 (1984).

54. The probability of detection may also depend on the availability of private forms of monitoring, including union complaints and citizen suits. See John T. Scholz, Can Government Facilitate Cooperation? An Informational Model of OSHA Enforcement, 41 AM. J. POL. SCI. 693 (1997) (finding that OSHA inspections prompted by worker complaints serve to reduce in juries without regard to the amount of penalty imposed).

55. Admittedly, people generally express little interest in or even understanding of probability in their decision making. See James K. Hammitt \& John D. Graham, Willingness to Pay for Health Protection: Inadequate Sensitivity to Probability?, 8 J. RISK \& UNCERTAINTY 33 (1999); Robin M. Hogarth \& Howard Kunreuther, Decision Making Under Ignorance: Arguing with Yourself; 10 J. RISK \& UNCERTAINTY 15 (1995); Oswald Huber, Roman Wilder \& Odilo Huber, Active Information Search and Complete Information Presentation in Naturalistic Risky Decision Tasks, 95 Acta Psychologica 15 (1997); Howard Kunreuther, Nathan Novemsky \& Daniel Kahneman, Making Low Probabilities Useful, 23 J. Risk \& UnCERTAINTY 103 (2001); Cass Sunstein, Probability Neglect: Emotions, Worst Cases, and Law (Mar. 2002) (unpublished manuscript), available at www.ksg.harvard.edu/cbg/Events/Papers/RPP_4-2-02_Sunstein.pdf. In addition, ordinary people do not appear to favor taking the probability of detection into account when setting penalty levels. Sunstein et al., supra note 8, at 1167 n.50; Cass R. Sunstein, David Schkade \& Daniel Kahneman, Do People Want Optimal Deterrence?, 29 J. LEGAL STUD. 237, 241-44 (2000). That said, this does not mean that the probability of detection is irrelevant to considered judgments about the sensibility of civil penalties for regulatory violations. Both regulators and analysts accept that administrative penalties are intended to provide deterrence and to give regulatory officials tools to affect behavior in order to achieve socially desirable goals. Moreover, not everything that is important is immediately understood or valued by the public. Even though Sunstein et al. argue that people have little interest in global coherence, for example, they do not conclude that coherence is for that reason irrelevant to the design of good and just public policy. 
penalties that require a court determination at the outset in order to be imposed. ${ }^{56}$ In their study of regulatory enforcement, Eugene Bardach and Robert Kagan noted the trend toward authorizing regulatory agencies to impose penalties without first having to go to court, observing that while "[m]ost agency-assessed civil penalties, such as those imposed by OSHA, are not large, ... they are swift and according to our interviews, are troubling even to very large corporations." 57 A penalty presumably does not need to be quite as large if it is swift and certain. ${ }^{58}$ Those who seek to compare penalties across regulatory categories would do well therefore to consider the differences in how penalties are imposed on violators.

\section{H. Implications for Judging Incoherence}

As this review of additional considerations suggests, variation in factors other than simply the seriousness of the regulatory goal can justify variation in the amount of civil penalties. Once additional factors such as those described above are taken into account, the differences between OSHA and Fish and Wildlife Service penalties do not appear to be as obviously incoherent at they initially may have seemed. First, the statutory penalties for OSHA violations are in fact substantially higher than the penalties for importing wild birds once the category of OSHA penalties for willful violations is used for comparison. Second, OSHA penalties are backed up by other significant behavioral incentives for workplace safety, including workers' compensation and tort liability, whereas penalties for wildlife regulations are not. Finally, unlike the Fish and Wildlife Service, OSHA has injunctive relief available to it that can result in additional, significant costs imposed on firms that threaten worker safety.

Of course, I make no claim to have fully analyzed all the differences between OSHA and Fish and Wildlife Service penalties, let alone the pattern of available or actually imposed penalties across other agencies. ${ }^{59}$ Nevertheless,

56. See Thunder Basin Coal Co. v. Reich, 510 U.S. 200, 210-11 (1994) (discussing congressional decision to streamline the process of imposing civil penalties under the 1977 Mine Act in order to enhance the deterrent effect of the penalties).

57. BARDACH \& KAGAN, supra note 24, at 52.

58. Moreover, the larger the penalty, the greater the incentive a firm has to contest its imposition, thus reducing the likelihood it will be imposed. See Surabhi Kadambe \& Kathleen Segerson, On the Role of Fines as an Environmental Enforcement Tool, $41 \mathrm{~J}$. ENVTL. PlanNing \& MGT. 217 (1998).

59. It is possible that the statutory maximum levels available to OSHA are too low when compared with those in other risk-based statutes, or that in practice the civil penalties imposed by OSHA and other agencies are less coherent than their statutory maximum levels would appear. We do know, for instance, that the average civil penalty issued by OSHA in some sectors amounts to less than a thousand dollars per violation. See, e.g., David Weil, Assessing OSHA Performance: Evidence from the Construction Industry, 20 J. PUB. POL. \& 
taking into consideration a broader range of relevant factors makes it less obvious that disparate penalties make no sense. Furthermore, the reason for the difficulty in identifying incoherence of existing regulatory policy is only partly the individual cognitive tendencies emphasized by Sunstein et al. The difficulty arises because of those tendencies combined with the complexity of regulatory policy and the conditions under which it is established and implemented. As challenging as it can be simply to determine how much more important worker safety is than the protection of wild birds, the cognitive demands become still greater when other dimensions of different regulatory problems are taken into account.

Unlike in the experimental setting, where researchers can control the factors that might affect individual judgments, identifying incoherence in practice demands attention to several dimensions all at once, because differences on one or more of these dimensions can sometimes justify variation in policies and outcomes. As a result, when viewed along one dimension, regulatory policies may appear incoherent, but when other factors are taken into account the policies may well make better sense. Of course, it is also possible that in some cases they will make even less sense. The point is that if we only look at one dimension at a time our judgments of incoherence will themselves be bounded and quite possibly mistaken. Furthermore, since variation across several dimensions will almost always be greater across rather than within regulatory categories, this will exacerbate if not even help explain the difficulties people experience in identifying across-category incoherence.

\section{IMPLICATIONS FOR REGULATORY INSTITUTIONS}

People's tendency to focus on just one dimension when judging the coherence of different policies extends beyond the realm of administrative penalties. Some of the most prominent illustrations of regulatory incoherence are studies focusing on the cost-effectiveness of different regulations in terms of saving lives. In the 1980s, the Office of Management and Budget released a table purporting to show wide variation in the cost-effectiveness of regulations across various domains, a table which has been revised, expanded, and cited widely in debates over regulatory reform. ${ }^{60}$ More recently, Tammy Tengs and her colleagues undertook an extensive study which found remarkable variation in the costs per life-year-saved across regulatory realms, from a median of $\$ 23,000$ per life-year-saved at the Federal Aviation Administration to a median

MGMT. 651, 656 tbl.2 (reporting that the total OSHA inspection of a construction site resulted in penalties of $\$ 711$ ).

60. See Sunstein et al., supra note 8, at 1198 (noting that the OMB table "has come to dominate many discussions of these problems"). See generally Lisa Heinzerling, Regulatory Costs of Mythic Proportions, 107 YALE L.J. 1981 (1998) (detailing the history and prominence of the OMB table and questioning its validity and relevance). 
of $\$ 7.6$ million per life-year-saved at the Environmental Protection Agency. ${ }^{61}$ Sunstein et al. point to this variation in the cost-effectiveness of regulations, suggesting that it reveals more predictable incoherence brought about by cognitive tendencies. They even include in their article a table of government regulations showing economic costs ranging from $\$ 100,000$ to $\$ 5.7$ trillion per life saved. ${ }^{62}$

Wide variation in the cost-effectiveness of different regulations has become a matter of concern because it suggests that society could save more lives for the same commitment of resources if government were to reallocate its priorities. $^{63}$ However, for the purpose of assessing the coherence of regulatory standards, a focus on their cost-effectiveness in terms of saving lives is actually quite narrow and even potentially misleading. ${ }^{64}$ The cost-effectiveness analysis that has dominated regulatory reform debates has focused attention on only one dimension of these regulations, albeit an important one-namely their impact on saving lives. A better approach would be to use an efficiency test that takes into account all the costs and benefits of different regulations.

Regulations can achieve a wide range of social benefits over and above saving lives. As Tengs and her coauthors acknowledge, "interventions that reduce fatal injuries in some people may also reduce nonfatal injuries in others; interventions designed to control toxins in the environment may have shortterm effects on [saving lives], but also long-term cumulative effects on the ecosystem." 65 As a result, cost variation that appears to make no sense when viewed simply in terms of lives saved could, in principle, make sense when these other social benefits are taken into account. ${ }^{66}$ After all, a given regulation

61. Tammy O. Tengs, Miriam Adams, Joseph S. Pliskin, Dana G. Safran, Joanna E. Siegel, Milton C. Weinstein \& John D. Graham, Five-Hundred Life-Saving Interventions and Their Cost-Effectiveness, 15 RISK ANALYSIS 369, 371 (1995). For a recent comparison of the cost effectiveness of environmental regulations, see Robert Hahn \& Robert N. Stavins, National Environmental Policy During the Clinton Years, in AmERICAN ECONOMiC POLICY IN THE 1990s 583, 630 tbl.9.8 (Jeffrey A. Frankel \& Peter R. Orszag eds., 2002) (reporting costs per statistical life saved in a dozen environmental regulations ranging from $\$ 9.4$ billion to $\$ 40.7$ billion).

62. Sunstein et al., supra note 8, app. E, at 1214-1215.

63. Tammy O. Tengs \& John D. Graham, The Opportunity Costs of Haphazard Social Investments in Life-Saving, in RISKS, COSTS, AND LIVES SAVED: GETTING BETTER RESUltS FROM REGULATION 167, 177 (Robert W. Hahn ed., 1996) (reporting that an additional 60,200 lives could be saved each year by reallocating social investments across nearly 200 lifesaving strategies).

64. See Hahn \& Stavins, supra note 61 , at 630 n.87 (noting that " $[\mathrm{t}] \mathrm{o}$ the extent that there are important nonmortality benefits, these [cost-per-life saved] studies may be misleading"); Cass R. Sunstein, Cognition and Cost-Benefit Analysis, 29 J. LEG. STUDIES 1059,1076 (2000) ("By itself, [a cost-effectiveness] table is insufficiently informative to tell people what they need to know.").

65. Tengs et al., supra note 61, at 372 .

66. See Robert W. Hahn, Regulatory Reform: What Do the Government's Numbers Tell Us?, in Risks, Costs, AND Lives SAVEd: GetTing BetTer Results From Regul.a tion, 
may well save only a few lives but prevent a vast number of nonfatal injuries or illnesses. It might make sense to adopt a regulation that would cost hundreds of millions of dollars per life saved if the regulation would also cure the common cold or prevent other more debilitating but nonfatal diseases.

For this reason, the overall coherence of risk-related regulatory standards would be better judged by taking a broader perspective, just as in the case of civil penalties. Such a broad view would not only take into account all the social benefits, but would also take into consideration factors such as distributional equity. ${ }^{67}$ Consideration of all the relevant factors may well make sense out of regulatory standards that appear to make little sense when viewed along just one dimension, such as cost-effectiveness. ${ }^{68}$

Of course, no one has yet shown that the overall pattern of risk regulation currently in place is, all things considered, an optimal and coherent one, and it would be surprising if anyone could. The available evidence certainly appears to indicate otherwise. ${ }^{69}$ My point here is simply that judgments of regulatory

supra note 63, at 208, 229 ("[C]alculations that rely on cost-effectiveness to reallocate resources may be misleading because the ordering of cost-effectiveness measures may not be highly correlated with the ordering of net benefits associated with those measures."). In addition, even when focusing only on mortality reduction, it may matter whether the lives to be saved from a regulation are younger or older persons' lives. For this reason, some analyses value mortality benefits based on life-years rather than just lives saved. U.S. Environmental Protection Agency, Guidelines for Preparing Economic Analyses, No. EPA$\begin{array}{lcccc}\text { 240-R-00-003, } & 91 & \text { (Sept. } & \text { 2000), } & \text { available } \\ \text { http://yosemite.epa.gov/ee/epa/eed.nsf/pages/guidelinesfiles/\$file/Guidelines.pdf. }\end{array}$

67. Matthew D. Adler \& Eric A. Posner, Rethinking Cost-Benefit Analysis, 109 Y ALE L.J. 165, 246 (1999) (arguing that "[cost-benefit analysis] must give way to important nonwelfarist concerns, such as deontological rights. An agency should not approve a project that has a positive [net utility] if it involves the unjustified sacrifice of an innocent."); Kenneth J. Arrow, Maureen L. Cropper, George C. Eads, Robert W. Hahn, Lester B. Lave, Roger G. Noll, Paul R. Portney, Milton Russell, Richard Schmalensee, V. Kerry Smith \& Robert N. Stavins, Is There a Role for Benefit-Cost Analysis in Environmental, Health, and Safety Regulation?, 272 SCIENCE 221, 222 (1996) ("Factors other than aggregate economic benefits and costs, such as equity within and across generations, may be important in some decisions."); Richard H. Pildes \& Cass R. Sunstein, Reinventing the Regulatory State, 62 U. CHI. L. REV. 1, 9 (1995) ("Regulations should be evaluated not only in terms of aggregate costs and benefits, but also in terms that reflect democratic judgments about qualitative differences among qualitatively different risks.").

68. People may think, for example, that it is especially important to protect poor children from a certain risk in a geographically isolated area, and they may be willing to devote an unusually large amount to ensure that protection. What seems to be a cognitive error may turn out, on reflection, to be a judgment of value, and a judgment that can survive reflection.

Sunstein, supra note 64, at 1073; see also Celia Campbell-Mohn \& John S. Applegate, Learning from NEPA: Guidelines for Responsible Risk Legislation, 23 HARV. ENVTL. L. REV. 93, 111 (1999) ("[I]t is unwise to set out a single substantive standard for all regulation in the multifarious areas of federal activity without a full inquiry into the important differences among the various areas.").

69. For example, Robert Hahn has attempted to parse through the of ten incomplete data on nonfatal injuries and diseases in calculating the net benefits of a sample of environmental and health and safety regulations. Based on various agencies' studies, he 
incoherence which are based solely on the cost-effectiveness of saving lives are themselves bounded and potentially misleading. ${ }^{70}$ Taking a broader perspective when making judgments about incoherence will yield different conclusions than result from a comparison made along just one dimension at a time. ${ }^{71}$

Even though cost-effectiveness of lives saved is at best an incomplete measure of regulatory coherence, it has dominated discussions of regulatory reform in large part because of the relative lack of standardized data needed to use a broader measure such as net social benefits. ${ }^{72}$ Methods of analysis vary greatly across regulatory realms, constraining analysts' and decisionmakers' ability to make reliable comparisons of a broader range of social benefits. In some realms decisionmakers rely on cost-effectiveness analysis of lifesaving interventions, while in other realms they seek to discern net benefits. ${ }^{73}$ Different agencies use different methods of valuation and different discount

concludes that many regulations still fail to yield positive net benefits, even when benefits in addition to mortality reduction are estimated. Hahn, supra note 66, at 219-221.

70. Hahn has shown that "[c]ost-effectiveness is quite sensitive to the measure that is used," potentially varying by more than a factor of ten depending on how effects other than fatalities are treated. Id. at 229. See also Adler \& Posner, supra note 67, at 230 (arguing in favor of cost-benefit analysis because it is a multidimensional approach to decision analysis, capable of incorporating a wide range of factors).

71. Moreover, judgments about the cost-effectiveness of risk regulation can be affected by other data flaws. For example, the variation in cost-effectiveness across regulations may not be as wide as it would appear from the original and of t-cited OMB table, since many of the most costly regulatory proposals included in that particular table were never promulgated. Heinzerling, supra note 60, at 2010. Furthennore, as others have acknowledged, the sample of regulations commonly used as a basis for judging the costeffectiveness of regulation is not a random one. Tengs et al., supra note 61, at 372 (noting that their analysis may be affected by selection bias because it is not a random sample of all life-saving interventions). As a result, it may be the case that the "larger view of the broader regulatory landscape" would show that there are "far more numerous examples of balanced, sensible, and cost-effective regulations." BREYER, supra note 4, at 28. Efforts to respond to incoherence may also be motivated by an overestimation of the problem because extreme anomalies are probably more readily available than are sensible consistencies. See Christine Jolls, Cass R. Sunstein \& Richard Thaler, A Behavioral Approach to Law and Economics, 50 STAN. L. REV. 1471, 1477 (1998) (discussing the effects of the availability heuristic on decisionmaking).

72. Cost-effectiveness analysis also avoids controversies that surround the valuation of human lives and the kinds of cognitive difficulties that attend to valuing other social benef its in monetary terms. Nevertheless, there would almost certainly be more attention to comparing net benefits across agencies than at present if there were better, more standardized data available.

73. For an interesting comparison of the variation in analytical methods used in the environmental and medical fields, see Janice Claire Wright, Investments that Save Lives: The Norms of Environmental and Medical Decision Making 2-14-2-20 (1997) (unpublished Ph.D. dissertation, Harvard University) (on file with the Stanford Law Review). 
rates. Many agencies do not quantify social benefits. ${ }^{74}$ Others are prohibited by statute from considering the costs of their decisions. ${ }^{75}$ With varied decisionmaking standards and analytic methods across and within regulatory realms, it is exceedingly difficult to gather and systematically compare data in order to provide a more comprehensive evaluation of regulatory coherence.

Sunstein et al. are right to observe that "[a]s things now stand, the structure of those institutions charged with making regulatory and legislative decisions reinforces the effects of category-bound thinking."76 The same fragmented institutional environment that reinforces category-bound thinking also produces category-bound data and analysis. Policymaking takes place in decentralized, diffuse, and circumscribed environments. The organization of the legislative branch of government into a myriad of committees and subcommittees leads to a high level of specialization. ${ }^{77}$ The people who work on and lobby for a given set of issues tend to be different people than those who work on similar issues in other networks or regulatory cultures. ${ }^{78}$ The network of relationships in Washington, D.C. exhibits a "hollow core," with very few individuals working across different policy areas. ${ }^{79}$

The presence of multiple decisionmakers, each possessing different and perhaps even changing preferences, makes inconsistent decisions likely, if not inevitable, when statutes and regulatory agencies are created at different times and for different purposes. ${ }^{80}$ Even if actors were to take cognizance of policies in other categories, policy agendas tend to emerge around focal points and crises du jour. ${ }^{81}$ Policy decisions necessarily reflect the composition of the prevailing political coalition, which itself changes over time. Even if the decisionmakers were always the same (or their preferences were), their collective decisions would not likely be coherent if their individual preferences

74. Robert W. Hahn, Jason K. Burnett, Yee-Ho I. Chan, Elizabeth A. Mader \& Petrea R. Moyle, Assessing Regulatory Impact Analyses: The Failure of Agencies to Comply with Executive Order 12,866, 23 HARv. J.L. \& PUB. POL'Y 859, 869-70 (2000).

75. See, e.g., Whitman v. Am. Trucking Ass'ns, 531 U.S. 457, 471 (2001) (holding that the Clean Air Act precludes the EPA from considering costs in setting national ambient air quality standards).

76. Sunstein et al., supra note 8, at 1156.

77. See Keith Krehbiel, Information and Legislative Organization 4-6 (1991).

78. Errol Meidinger, Regulatory Culture: A Theoretical Outline, 9 LAW \& POL'Y 355, 364-65 (1987); Hugh Heclo, Issue Networks and the Executive Establishment, in THE NEW AmERICAN POLITICAL SYSTEM 87, 99-100 (Anthony King, ed., 1978).

79. John P. Heinz, Edward O. Laumann, Robert L. Nelson \& Robert H. Salisbury, The Hollow Core: Private Interests in National Policy Making 236-37 (1993).

80. See Jerry L. Mashaw, Bureaucratic Justice: Managing Social Security Disability Claims 55 (1983) (observing that "[s]ocial policy as legislatively crafted into programmatic directives should not be expected to emerge as a set of fully coherent approaches to unitary goals").

81. John W. Kingdon, Agendas, Alternatives, and Public Policies 17-18 (1984). 
fall across more than one dimension. ${ }^{82}$ It seems plausible that the two kinds of coherence I have distinguished here, namely instrumental and comparative coherence, are not well correlated and in fact may align along different dimensions. If so, then even if all policy actors were fully to consider both kinds of coherence, their policy preferences could be arrayed in such a way as to make impossible a coherent collective ordering of their preferences for different kinds of coherence.

To be sure, policy fragmentation and the diffusion of multiple actors has its defenders, and for good reason. ${ }^{93}$ Robust, pluralistic policymaking may well be less coherent than rule by elite guardians, but its messiness could simply be a necessary price of democratic decisionmaking. ${ }^{84}$ In addition, dividing up the policy space can encourage the kind of specialization needed to enact policies that make more instrumental sense, and perhaps at the end of the day that matters more than complete comparative coherence. ${ }^{85}$ A division of policymaking authority may also foster healthy competition and the kind of innovation that is necessary for a good legal system. ${ }^{86}$

The irony, of course, is that the same fragmentation that reinforces category-bound thinking and leads to incoherent policy judgments also confounds efforts to assess and address the problem of incoherence due to the resulting incompatibilities in methods of data collection and policy analysis. To evaluate regulatory incoherence in a systematically coherent way, those interested in improving govemment regulation will need to consider more than just one dimension of regulatory policies at a time and will need standardized data across these various dimensions. They will need to seek to understand better whether incoherence exists, how significant and pervasive it is, and whether gains in coherence would be worth any possible costs in terms of the

82. Kenneth J. ARrow, Social. Choice and Individual Values 10-11 (1951).

83. As Sunstein et al. note, "coherence is not a trumping value, and a system displaying incoherence may well be better than one that is coherent but pervasively unjust." Sunstein et al., supra note 8, at 1203.

84. Robert A. Dahl, Democracy and Its Critics 78-79 (1989).

85. The absence of intercircuit stare decisis among appellate courts, for example, would seem inevitably to lead to incoherence since it pennits a national law to be interpreted and administered in one circuit in ways that are completely at odds with how it is interpreted and administered in another circuit. Yet it has been argued that this approach fosters intercircuit dialogue that "is likely to result in better decisions, as it will produce a more careful and focused consideration of the issues." Samuel Estreicher \& Richard L. Revesz, Nonacquiescence by Federal Administrative Agencies, 98 YALE L.J. 679, 736 (1989). For a similar discussion suggesting that the fragmented organizational structure of the U.S. Congress may promote better policymaking, see KREHBIEL, supra note 77 , at 245; KING, supra note 5, at 144-45..

86. For example, Japan's system of compensation for automobile accidents is thought to be more coherent than that found in the United States, but Japan has achieved its greater consistency by creating a more rigid, less adaptable legal system, which may create problems of its own. Takao Tanase, The Management of Disputes: Automobile Accident Compensation in Japan, 24 LAw \& SoC'Y REv. 651, 681 (1990). 
values served by pluralistic diffusion. ${ }^{87}$ Perhaps this is partly what Sunstein et al. have in mind when they acknowledge that it is not "easy or even possible for people to agree on what full coherence actually requires."ss In addition to the difficulty of agreeing on full coherence, however, it may also be neither easy nor possible for people to agree on what the obvious anomalies are, or on whether and how to address them.

\section{CONCLUSION}

Sunstein et al.'s article raises important concerns about regulatory policy and the design of regulatory institutions. In articulating a cognitive basis for incoherent decisionmaking and identifying extensive, even puzzling, variation in regulatory policies, they lay down an ambitious challenge for reducing incoherence across regulatory policies. Yet in calling attention to some of the predictable consequences of making policy one case at a time, they also reveal that these same cognitive tendencies, in particular category-bound thinking, can affect judgments about the incoherence of government regulation. Evaluations of regulatory incoherence can be, and perhaps predictably will be, bounded themselves. For this reason, rooting out incoherence will be more difficult than might be hoped, because policies that appear incoherent when evaluated narrowly may not be so incoherent after all. Policy differences that appear to be incoherent will in some cases instead be fully justified. The challenge for those who share the aspiration for systematic rationality in law is therefore to probe still more deeply and more broadly, and to search for a better understanding of the extent of regulatory incoherence, the tensions between instrumental and comparative coherence, and the institutional reform strategies that will ultimately make the most sense.

87. Efforts such as the OMB's guidelines for economic analysis are a step in the direction of creating a more uniform system of data collection and analysis. Office of Management and Budget, Office of Information and Regulatory Affairs, A Report to the President on the Third Anniversary of Executive Order 12866 (Dec. 1996), available at http://www.whitehouse.gov/omb/inforeg/riaguide.html; Office of Management and Budget, Of fice of Information and Regulatory Affairs, Guidelines to Standardize Measures of Costs and Benefits and the Format of Accounting Statements (2000), available at http://www.whitehouse.gov/omb/memoranda/m00-08.pdf. The literature is also replete with suggestions for improving the quality and the impact of cost-benefit analysis in regulatory policymaking. See, e.g., Arrow et al., supra note 67, at 222; Hahn, supra note 66, at 240-44. See also U.S. Environmental Protection Agency, supra note 66.

88. Sunstein et al., supra note 8, at 1203. 